\title{
Research on Ancient Chinese Literature History from Time Dimension to Spatial Dimension
}

\author{
Chengxiu Teng \\ School of Public Administration \\ Zhongnan University of Economics and Law \\ Wuhan, China
}

\author{
Wanyu Guo \\ Wuhan Finance School \\ Wuhan, China
}

\begin{abstract}
The research on the history of ancient Chinese literature is used to focus on the Han nationality writers, Chinese language and literature works and related literary themes in the Central Plains. The history of ancient literature is mostly observed from the perspective of single region and nation, and the time dimension is dominant in narrative discourse, so the impact of exploring geographical space on various related elements in literary history is slightly weak. This paper intends to discuss the issues related to the history of ancient Chinese literature from the perspective of time to spatial dimensions, and proposes relevant implementation paths and methods.
\end{abstract}

Keywords-time dimension; spatial dimension; history of ancient Chinese literature

\section{INTRODUCTION}

In the traditional discourse system, the focus of the research on the history of ancient Chinese literature is the Han nationality literature in the Central Plains. The narrative discourse mostly explores the historical development and process of the research object from the time dimension. Although some literary history narrators also have a description of space in the expression of time dimension, such as the birthplace of the writer and the geographical trajectory of his life activities, he even categorizes the writers and their works in the same region, such as the "the Gong an school" and "Jingling School" in the Ming Dynasty [1]. However, under the strong leadership of the time dimension, the spatial perspective is often neglected, and the richness and diversity of ancient literature and its history are difficult to be explored, which will inevitably have an adverse impact on the in-depth analysis and research on ancient Chinese literature. Therefore, this paper intends to explore the theoretical value of the history of ancient Chinese literature from the perspective of time to space, and deepen the theoretical research in related fields.

\section{THE NECESSITY FOR EXPANDING THE SPATIAL} DIMENSION OF HISTORICAL STUDY ON ANCIENT CHINESE

\section{LITERATURE}

Objectively speaking, the research on the history of ancient Chinese literature is a long-term and arduous task. Getting rid of the narrative of time narrative and investing the perspective in a broader space will help us better understand the development of the history of ancient Chinese literature and the law of evolution.
A. The Overall Perspective of Literary History: Expanding the Spatial Perspective Helps to Deepen the Overall Theory of the History of Ancient Chinese Literature

The field of Chinese ancient literature has long been confined to Han nationality literature. It has deliberately and unconsciously ignored the literary works of other ethnic minorities in China and its writers. In particular, the textbooks on Chinese mainland, HongKong and Taiwan literature history in modern times basically belong to the literary history narrative of the Han nationality. For example, the narrative poems of ancient Chinese ethnic minorities have never been more prosperous. The existing 55 ethnic minorities have appeared their own narrative poems in the history. Among them, the outstanding representatives are the Mongolian "Epic of Jangar" and the Kirgiz's "Manas" and so on [2]. The emergence of this phenomenon is closely related to the longclosed history of the Central Empire and the narrow-minded thoughts of Barbarians outside the Central Plains. It is expressed in the narrative of literary history. Naturally, it lacks a reflection on the minority literature and its history belonging to the "barbarians".

We must break through the existing research pattern of ancient Chinese literature history. The key is to abandon the misconceptions that ancient Han nationality and its literature can represent ancient Chinese literature, and expand the research horizon and the scope of research to other ethnic minority areas beyond the core area of the Central Plains to form a discourse system of ancient Chinese literature covering Han and other minority literature.

First of all, the ancient literature of ethnic minorities has a unique and complete development system, and there are many outstanding literary works and poets, which is an integral part of the Chinese cultural circle literature as well as Chinese literature. China has been a multi-ethnic country since ancient times, and the Han nationality and other ethnic minorities have continued to blend. The so-called Central Plains culture is also the crystallization of multi-ethnic culture integration: therefore, ancient Chinese literature should also be multi-ethnic ancient literature in nature, so ancient literature of ethnic minorities is an important part of it [3].

Secondly, the blending of ancient literature of ethnic minorities and Han nationality helps the Han people and the ethnic minorities learn from each other. The Southern and 
Northern Dynasties were the key nodes for the great integration of ethnic groups in the ancient Chinese history and the great exchange of culture and art. During this period, nomadic minorities in the north, such as the Xiongnu, Xianbei, Sui and Qiang, successively entered the Central Plains and led the majority of the Central Plains. Under such a historical background, the mixed exchanges between the Han people of the Central Plains and the ethnic minorities in the north was increased, and ethnic integration was accelerated. Ethnic minorities wore Chinese clothes, learned Chinese, learned the production and life style of the Han people, and gradually changed their nomadic life into farming life. The absorption of the Han traditional culture, especially the Confucian culture, has improved the overall cultural level of the nation. The process of the localization of this minority is mutually beneficial to both sides, and it also enhances the literary collision and exchange between the various ethnic groups.

It is worth noting that the study of Han literature in minority literature is not simply for Chinesization and the loss of self, and thus the loss of its distinctive literary features. Their absorption of the Han culture belongs to the improvement of the national literature, and it is the blending of two or more national cultures. This kind of blending is quite successful and has achieved fruitful results. At the same time, in the long-term contact with the northern minorities, the Han literature has been used for multi-level and useful reference and absorption of minority literature nutrients and integrated into its own literary system. For example, most of the folk songs of the Northern Dynasties are ethnic minorities in the north. Many of their works have been searched into Yuefu, forming the folk songs of the Northern Dynasty that we saw today, adding a lot of masculinity to ancient Chinese literature.

Of course, it is easier for us to see the influence of the northern minority literature in the Northern Dynasty on the literature of the Tang Dynasty, especially the frontier poetry. The main style of frontier poetry in Tang Dynasty is strong and heroic. It is obvious that it has deep roots with the folk songs of the Northern Dynasties and is strongly influenced by the Northern Dynasty literature and minority literature. The frontier poetry of the Tang Dynasty absorbed the most fascinating part of the folk songs of the Northern Dynasties. It not only possessed the magnificent vicissitudes of the folk songs of the Northern Dynasties, but also the original wild style of the original style. It also possessed the natural and innocent feelings of the northern poets. The frontier poetry of the Tang Dynasty can reflect the unrestrained and straightforward characteristics of the folk songs of the Northern Dynasties. It is the continuation of the national literature of the Southern and Northern Dynasties in the prosperous Tang Dynasty.

In summary, the history of minority literature is an important part of the history of ancient Chinese literature from the elements of ancient literature history. The marriage between minority literature and Han literature is difficult to completely separate from each other. Therefore, minority literature should receive more attention in the geographical space.
B. Theoretical Macroscopic Perspective: Expanding the Spatial Dimension Helps to Deepen the Understanding of the Macroscopic Thoughts and Styles of the History of Ancient Chinese Literature

The influence of geographical space on literary works and literary history is multi-dimensional. Due to the vast territory, ancient Chinese literature has distinct regional characteristics. For example, the Chu- Ci produced in the Yangtze River Basin, the "folk Song" produced in deep areas of the frontiers, etc., are different expression given to different literary works by different regions. In fact, the geographical space not only affects the production of literary style, but also plays an important role in the content, style and genre of literary works. Geographical space construction of ancient Chinese literary works is mainly divided into the following types: single space type, the combination of real-virtual space, single space timesharing type, multiple time-space type and other modes. [4]

1) Single-space type: Take Five-character quatrains "River Snow" of Tang Dynasty as an example: "there is no bird among mountains or people on the paths, only a fisherman on the boat, dressed in a robes and fishing alone on the snowy river." (Author: Liu Zongyuan). This poem was written by the author when he was sent to Yongzhou (now Yongzhou City, Hunan Province) as a Sima (an official position in army). In the poem, the author constructs a vast space without a border, such as "Mountains" and "paths", and this space is alone. The "fisherman" is like the protagonist of the one-act play, performing a one-man show. The poet has a strong sense of loneliness.

2) The combination of real-virtual space: Take the sevencharacter quatrain "recalls the brothers in Shandong on 9thSeptember" in the early Tang Dynastyas an example: "I can't be reunited with my family when I am away from home, Every time I go to the Double Ninth Festival, I miss my loved ones particularly. When I know that my brothers in Shandong climbed up the mountains to plant cornel, they will also feel regret because they are one less. "(Author: Wang Wei). This poem was written by the author when he was 17at Chang'an, the capital of the time. In the poems, he built the space far away from home and Shandong, a real and virtual one, expressing his loneliness as a stranger and the sore miss to family and hometown.

3) Single space time-sharing type: Take the sevencharacter quatrain of the Mid-Tang Dynasty "Inscription to Ducheng Nanzhuang", as an example: "Last winter I came here, the girl was beautiful and the peach flowers were bright. When I came here this year, the door was closed and the girl left, only the peach blossoms still greeted the spring breeze." (Author: $\mathrm{Cui} \mathrm{Hu}$ ). This poem narrates that the author visited the south of the capital alone during the Qingming Festival last year, and met the beautiful and exciting girl. While Today, The things are still there, but men are no more the same one. In the same space, at different times, people's moods are completely different, and the author's endless sense of loss is on paper.

4) Multiple time-space type: take the seven-character quatrain "writing to the North on a rainy night" in the late Tang Dynasty as an example, "When you ask me when I go home, the date I go home will not be fixed! The only thing I 
can tell you at this time is that it is full of the endless rains of Bashan. If there is such a day, we will sit together under the western window of the house to cut the window sticks, and talk to each other about the feelings on the rainy night in Bashan!" (Author: Li Shangyin). This poem was written in Zizhou (now Santai, Sichuan Province), which created two geographical spaces, Bashan in the south and west window in the north. It crossed the two different times of the moment and that of the wife receiving the letter, which constituted multiple artistic conceptions of different time and space. It vividly shows the author's loneliness, hardship, homesickness and hopefulness in his hometown.

\section{Theoretical Microscopicperspective: Expanding the Spatial Dimension Helps to Deepen the Individualized Study of Writers and Literary Works}

Generally speaking, creators, works and literary topics are the main objects of the research on ancient literary history. In the process of literary history, our research on creators, including individual writers and groups of writers distinguished by geography and genre, must first clarify the spatial location of these creators at that time, namely, specific creative scenes, including politics environment, living environment, social and ideological environment, etc., in order to provide an academic cognition basis for the research creators' ideological feelings, writing motivation, artistic accomplishment and other reasons. At the same time, the geographical environment of the writer will change continuously with the passage of time. This requires careful examination of the specific background and footprints of the writers and writer groups to form a clear geographical space research context.

In view of the fact that writers or writers groups are individuals or organizations of society, they constantly change the geographical space of life and creation in the specific era in which they live. Correspondingly, the political environment, living environment, and ideological environment also continuously change with time. The change is related to the writers and works. Therefore, we can integrate the political environment, living environment, ideological environment and time factors to form a unique four-dimensional examination method, make more detailed research on the creators and their works, and grasp the general rules of individualization. The time change of the main body of literary creation is closely related to the spatial transformation. The spatial environment changes with time and relates to time, which is the distinctive feature of the four-dimensional time and space examination. Through the examination of the four-dimensional space, we can further explore the creator's spatial survival and creative state, and accurately grasp the internal reasons for the formation and change of its creative content and style. In fact, in ancient China, it was a common situation for writers to seek spiritual survival in geographical space through the creation of literary geography space. In the history of ancient Chinese literature, perhaps literary creators may not consciously carry out the construction of literary geography space in his works, but his works often bear the mission of this cultural creation in practice [5].
In the same way, for the research on ancient Chinese literature, we must first clarify the different spatial positions that they are constantly changing with time, pre-determine the four-dimensional time and space of the works, and then transfer to other in-depth studies to achieve substantial results. As for the special research on ancient literature, including literary concepts, works changing and literary trends, or a comprehensive study of related literary works in a certain historical period, it can also be promoted in the way of fourdimensional time and space.

\section{CONCLUSION}

This paper briefly expounds the necessity and significance of spatial dimension for the research on literature history, which is of great benefit to break through the limits of time dimension, expand the research horizon of ancient Chinese literature history, construct a three-dimensional research framework, display a rich and diverse picture of literary history and deepen the understanding of the general laws of ancient Chinese literature and the exploration of theories.

In the process of practice and theoretical research, we can consider making contributions to the innovation of the academic method system of the Han nationality or the Oriental standard by drawing on the elaboration of Western scholarship and the method of empirical research. On the basis of familiar reading on the classical literature, the researchers combined the relevant theories of spatial dimension in the history of Western literature, and carefully studied the four-dimensional spatialtemporal interaction of the research objects, and used the academic methods combined with Chinese and Western to study its literary characteristics and the law of literature, evaluated the academic value under the guidance of the historical development concept in order to construct a more scientific and perfect academic method system suitable for China's national conditions.

\section{REFERENCES}

[1] Edited by Gou Lin. Tracing the source of Chinese traditional culture [M]: Shanghai: Shanghai Academy of Social Sciences Press, 2017.01: 513. (in Chinese)

[2] Editor-in-Chief Tang Xiaoqing. The side of history - The study of the 30 years of the study of the National Literature [M]: Beijing: Social Sciences Academic Press, 2015.08: 372. (in Chinese)

[3] Edited by Northwest University for Nationalities, College of Liberal Arts, Teaching Committee. Practice, Reflection, Innovation, Undergraduate Teaching Research Papers of Northwest University for Nationalities, [M]: Beijing: Nationalities Publishing House, 2012.05: 306. (in Chinese)

[4] Zeng Daxing. Introduction to Literary Geography [M]: Beijing: The Commercial Press, 2017.03: 478. (in Chinese)

[5] Editor-in-Chief Lei Xuefeng. World Literature Review 2014 Series 1 [M]: Shanghai: World Book Shanghai Publishing Company, 2014.05: 257. (in Chinese) 